\title{
Six-Axis Linkage Strategy and Its Models for Non-Circular Helical Gears Based on Diagonal Hobbing
}

\author{
Youyu Liu'1,2,* - Jiesheng Diao ${ }^{1,2}$ \\ 1 School of Mechanical and Automotive Engineering, Anhui Polytechnic University, China \\ 2 AHPU Institute of Technology Robotics Industry, Anhui Polytechnic University, China
}

\begin{abstract}
Among cutter teeth of the hob when hobbing non-circular helical gears, there are some issues such as uneven load and wear. To solve those problems, a simultaneous six-axis hobbing model had been developed based on diagonal hobbing. Four probable working conditions were provided. Linkage models corresponding to the four conditions were verified by virtual hobbing, in which the profile accuracies were compared and analyzed. The four working conditions were analyzed including linear (or angular) velocities and linear (or angular) accelerations. Consequently, two implementation strategies including repeating axial shift and reciprocating axial shift were offered. The linkage models and their strategies have been verified by hobbing testing. Experimental results show that diagonal hobbing is superior to non-diagonal hobbing in that the hob life of the former is 3.68 longer than that of the latter, and the micro-topography in the teeth surface of the former is more stable during transmission.
\end{abstract}

Keywords: non-circular helical gears, diagonal hobbing, linkage models, hob life

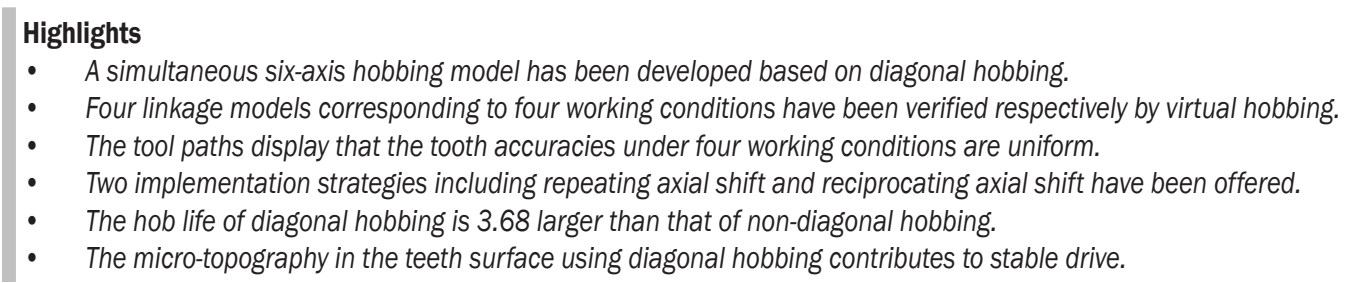

\section{INTRODUCTION}

As a result of the comprehensive combination of circular gears and cams, non-circular gears can deliver high output power accurately with continuously variable transmission and have been widely used in vehicles [1], agricultural machinery [2], fluid machinery [3], light industrial machinery [4], and so on. Numerous in-depth studies on the design and applications of non-circular gears have been carried out with great academic achievements in recent ten years [5] to [7]. However, the practical applications of non-circular gears are not commensurate with their numerous advantages with manufacturing technology lagging behind the research. Shaping and hobbing are two kinds of efficient cutting methods available for gears. We have realized the machining of non-circular helical gears using gear shaping [8] and [9].Tan et al. [10] have developed a basic mathematical model only for hobbing non-circular spur gears. Tian et al. [11] have built some basic mathematical models for hobbing non-circular helical gears, with helical teeth, by a generating method of helical tooling rack based on non-diagonal hobbing, but provided no processing program for them. We have constructed some hobbing schemes and linkage models based on a four-axis linkage [12] and a five-axis linkage [13], and have singled out two excellent strategies with their linkage models. All in all, those works make hobbing noncircular (spur or helical) gears possible and greatly improve the production efficiency in contrast to the classic wire electric discharge machining [14] that is used to machine non-circular spur gears. All the hobbing models above keep hobs fixed in their axial positions. Thus, only parts of the cutter teeth on the hob take part in hobbing. Moreover, it is a small fixed section of the cutting edge for each cutter tooth that actually takes part in hobbing. These cutting edges will be abraded continuously during the hobbing process, which will affect the shape accuracy of the tooth profile and its roughness. Load and wear among the cutter teeth of the hob are seriously uneven in hobbing using non-diagonal hobbing. The hob life depends on the cutter tooth that has the largest amount of wear. Thus, hob life in non-diagonal hobbing is extremely low.

In order to solve this problem, and to make the most use of all cutter teeth and make load and wear among them equal, a six-axis linkage strategy and its models for hobbing non-circular helical gears are developed according to a principle of diagonal hobbing in this paper. In this linkage strategy, the hob 
moves along its axis continuously while it is moving in a vertical direction. The linkage strategy and its linkage model have been verified to be correct and feasible by virtual hobbing, dynamics analysis, and hobbing testing. Finally, some practical applications are offered.

\section{LINKAGE STRATEGY BASED ON DIAGONAL HOBBING}

A simultaneous five-axis hobbing scheme [13] for non-circular helical gears is shown in Fig. 1. The projection of the hob in the cross-section of the gear billet is a rack. Thus, the hob spinning as $\omega_{\mathrm{b}}$ can form a tooling rack. $\omega_{\mathrm{c}}$ of the gear billet generates a meshing movement with $\omega_{\mathrm{b}}$, and both of them keep a strict transmission ratio. As shown in Fig. 2, the rotation of the pitch curve of the gear billet is a pure rolling along the midline of the tooling rack without slipping. The midline of the tooling rack is tangent to point $\mathrm{P}$ with the pitch curve of gear billet. To create a pure rolling, the gear billet should move along both $\mathrm{x}$-axis (namely $\mathbf{v}_{\mathrm{x}}$ ) and $\mathrm{y}$-axis (namely $\mathbf{v}_{\mathrm{y}}$ ) while it is spinning as $\omega_{\mathrm{c}}$. In order to cut a full-depth tooth, the hob should move along the z-axis (namely $\mathbf{v}_{\mathrm{z}}$ ). $\mathbf{v}_{\mathrm{z}}$ has a strict linkage with $\Delta \omega_{c}$, which can form a helical tooling rack to cut non-circular helical gears. In this scheme, the hob is fixed along its axle and the meshing point of the pitch curve is located on the fixed point $\mathrm{P}$ in space, and then only part of the cutter teeth around point $\mathrm{P}$ actually take part in the hobbing, which will radically reduce hob life and teeth accuracy.

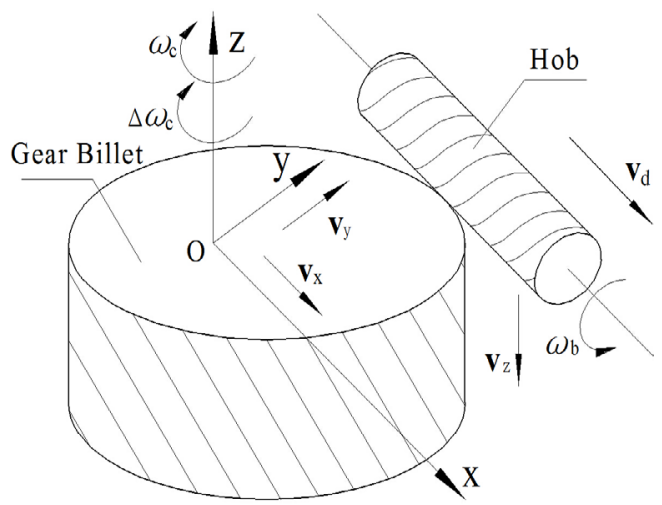

Fig. 1. Schematic diagram of hobbing process

Diagonal hobbing implies that hob continuously moves along its own axis so that all of cutter teeth take part in hobbing without damaging the original simultaneous five-axis motion. As shown in Fig. 2, a diagonal feedrate $\left(\mathbf{v}_{\mathrm{d}}\right)$ along the hob axis is added to the linkage system. The direction of $\mathbf{v}_{\mathrm{d}}$ along the hob axis conforms to the rule of right-hand corkscrew with $\omega_{\mathrm{b}}$ (marked as ' $\mathrm{U}$ '), and can also conform to a rule of a left-hand corkscrew (marked as ' $V$ ') [15]. From Fig. 2, we can see:

$$
\mathbf{v}_{\mathrm{b}}^{*}=\mathbf{v}_{\mathrm{b}}+\mathbf{v}_{\mathrm{dx}} \cdot
$$

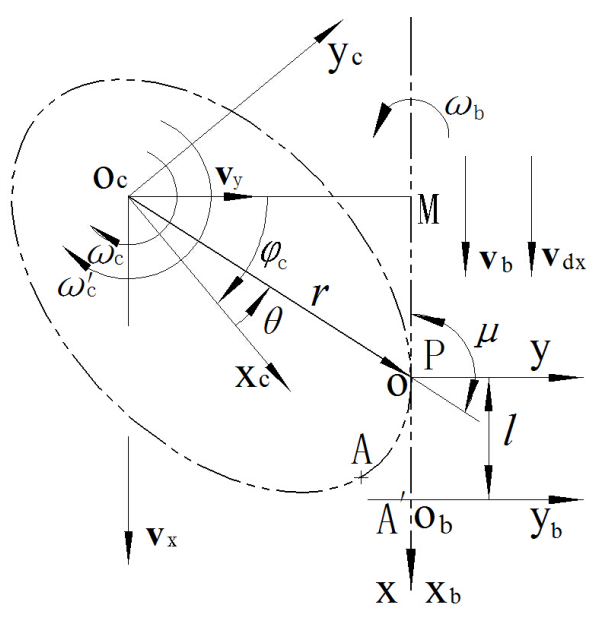

Fig. 2. Cross-section of gear billet

The original vertical movement $\mathbf{v}_{\mathbf{z}}$ of the hob creates a resultant velocity $\mathbf{v}_{\mathrm{z}}^{*}$ with $\mathbf{v}_{\mathrm{dz}}$. That is to say,

$$
\mathbf{v}_{\mathrm{z}}^{*}=\mathbf{v}_{\mathrm{z}}+\mathbf{v}_{\mathrm{dz}} \text {. }
$$

Just like circular helical gears, non-circular helical gears can be divided into two types: left-hand gears (marked as ' $L$ ') and right-hand ones (marked ' $R$ '). As shown in Fig. 3:

$$
\mathrm{v}_{\mathrm{d} z}=\mathrm{v}_{\mathrm{d}} \sin \left(\lambda_{\mathrm{b}} \pm \beta_{\mathrm{c}}\right),
$$

where the '-' is adopted for left-hand helical gears, the '+' for right-hand ones.

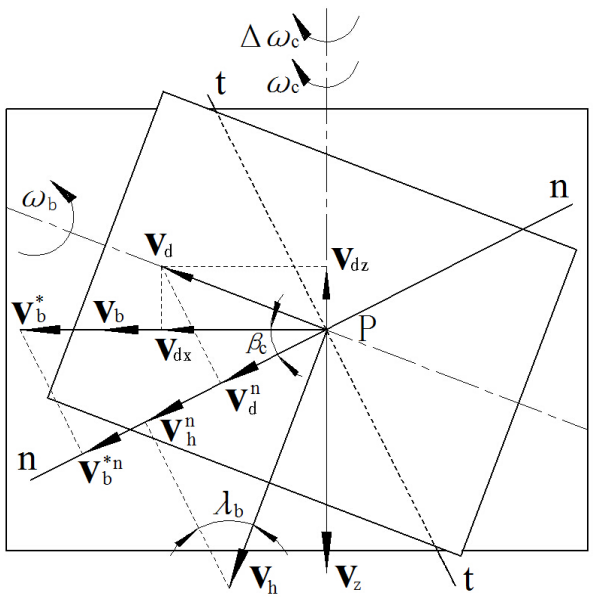

Fig. 3. Common tangent plane of hobbing 
A reasonable $\mathbf{v}_{\mathrm{z}}^{*}$ can be chosen according to the requirements of axial tooth accuracy, and then a proper $\mathbf{v}_{\mathrm{z}}$ can be determined by the value of $\mathbf{v}_{\mathrm{dz}}$. For a non-circular helical gear, the gear billet should rotate an additional cycle when $\mathbf{v}_{\mathrm{z}}^{*}$ moves a screw lead along the axle of the gear billet [16], from which the value of $\Delta \omega_{\mathrm{c}}$ is determined.

Thus, this diagonal hobbing is a simultaneous six-axis linkage method, which includes two implementing schemes: ' $U$ ' and ' $V$ '.

\section{LINKAGE MODELS BASED ON DIAGONAL HOBBING}

As shown in Fig. 2, $S(0-x y z)$ is located at point $\mathrm{P}$, where the $\mathrm{x}$-axis and the $\mathrm{z}$-axis are parallel to the pitch line of the hob and the shaft of the gear billet respectively. $S_{\mathrm{c}}\left(\mathrm{o}_{\mathrm{c}}-\mathrm{x}_{\mathrm{c}} \mathrm{y}_{\mathrm{c}} \mathrm{z}_{\mathrm{c}}\right)$ revolves with the gear billet, in which the origin lies in the rotation center of the gear billet and each axis is parallel with that of $S(\mathrm{o}-\mathrm{xyz})$ at the beginning. $S_{\mathrm{b}}\left(\mathrm{o}_{\mathrm{b}}-\mathrm{x}_{\mathrm{b}} \mathrm{y}_{\mathrm{b}} \mathrm{z}_{\mathrm{b}}\right)$ moves with the the tooling rack of the hob, which coincides with $S(\mathrm{o}-\mathrm{xyz})$ at the beginning. The polar equation of the pitch curve is $r=r(\theta)$. At the beginning, the polar axis and the y-axis are kept in superposition. The forward direction of $\varphi_{\mathrm{c}}, \theta$, and $\omega_{\mathrm{c}}$ are shown in Fig. 2. $\mu$ can be calculated according to Eq. (4) [16].

$$
\tan \mu=r /(d r / d \theta) \quad(0 \leq \mu<\pi),
$$

hence,

$$
\left\{\begin{array}{l}
\sin \mu=r / \sqrt{r^{2}+(d r / d \theta)^{2}} \\
\cos \mu=(d r / d \theta) / \sqrt{r^{2}+(d r / d \theta)^{2}}
\end{array}\right.
$$

from Fig. 2,

$$
\theta=\varphi_{\mathrm{c}}-\mu+\pi / 2
$$

From Eq. (4),

$$
\frac{d \mu}{d t}=\frac{(d r / d \theta)^{2}-r\left(d^{2} r / d \theta^{2}\right)}{r^{2}+(d r / d \theta)^{2}} \cdot \frac{d \theta}{d t} .
$$

Consequently, $\omega$ is as follows:

$$
\omega=\frac{d \theta}{d t}=\frac{r^{2}+(d r / d \theta)^{2}}{r^{2}+2(d r / d \theta)^{2}-r\left(d^{2} r / d \theta^{2}\right)} \omega_{c} .
$$

As shown in Fig. 2, since the midline of the tooling rack makes a pure rolling at point $\mathrm{P}$ with the pitch curve of gear billet, $l$ should be equal to $s$, as follows.

$$
l=s=\int_{0}^{\theta} \sqrt{r^{2}+(d r / d \theta)^{2}} d \theta .
$$

Then, $\mathbf{v}_{\mathrm{b}}^{*}$ is as follows:

$$
v_{\mathrm{b}}^{*}=v_{\mathrm{b}}+v_{\mathrm{dx}}=\frac{d l}{d t}=\sqrt{r^{2}+(d r / d \theta)^{2}} \cdot \frac{d \theta}{d t} .
$$

Eq. (8) is substituted in Eq. (10):

$$
v_{\mathrm{b}}^{*}=\frac{\left[r^{2}+(d r / d \theta)^{2}\right]^{3 / 2}}{r^{2}+2(d r / d \theta)^{2}-r\left(d^{2} r / d \theta^{2}\right)} \omega_{\mathrm{c}},
$$

$v_{\mathrm{x}}$ and $v_{\mathrm{y}}$ are as follows:

$$
\left\{\begin{array}{l}
v_{\mathrm{x}}=\frac{d(r \cos \mu)}{d t}=-r \sin \mu \frac{d \mu}{d t}+\cos \mu \frac{d r}{d \theta} \frac{d \theta}{d t} \\
v_{\mathrm{y}}=\frac{d(r \sin \mu)}{d t}=\sin \mu \frac{d r}{d \theta} \frac{d \theta}{d t}+r \cos \mu \frac{d \mu}{d t}
\end{array} .\right.
$$

Eqs. (5), (7) and (8) are substituted in Eq. (12),

$$
\left\{\begin{array}{l}
v_{x}=\frac{r^{3}\left(d^{2} r / d \theta^{2}\right)+(d r / d \theta)^{4}}{\sqrt{r^{2}+(d r / d \theta)^{2}}\left[r^{2}+2(d r / d \theta)^{2}-r\left(d^{2} r / d \theta^{2}\right)\right]^{2}} \omega_{c} \\
v_{y}=\frac{r(d r / d \theta)}{\sqrt{r^{2}+(d r / d \theta)^{2}}} \omega_{\mathrm{c}}
\end{array}\right.
$$

Due to the pure rolling, the tangent velocity of the gear billet at point $P$ should be equal to the translational speed $\mathbf{v}_{\mathrm{b}}^{*}$ of the tooling rack. As shown in Fig. 3, the normal components of the velocities $\mathbf{v}_{\mathrm{d}}, \mathbf{v}_{\mathrm{b}}^{*}$, and $\mathbf{v}_{\mathrm{h}}$ are $\mathbf{v}_{\mathrm{d}}^{\mathrm{n}}, \mathbf{v}_{\mathrm{b}}^{*_{\mathrm{n}}}$, and $\mathbf{v}_{\mathrm{h}}^{\mathrm{n}}$ are on the meshing point $\mathrm{P}$. The normal velocity of the gear billet at point $\mathrm{P}$ should be equal to that of the hob [11]. Thus,

$$
v_{\mathrm{h}}^{\mathrm{n}}+v_{\mathrm{d}}^{\mathrm{n}}=v_{\mathrm{b}}^{{ }_{\mathrm{b}} \mathrm{n}} .
$$

The value of $\mathbf{v}_{\mathrm{h}}$ is as follows:

$$
v_{\mathrm{h}}=K m_{\mathrm{t}} \omega_{\mathrm{b}} / 2=K m_{\mathrm{n}} \omega_{\mathrm{b}} /\left(2 \sin \lambda_{\mathrm{b}}\right) .
$$

From Fig. 3, and Eqs. (11), (14) and (15):

$$
\frac{K m_{\mathrm{n}} \omega_{\mathrm{b}}}{2}+\kappa v_{\mathrm{d}} \cos \lambda_{\mathrm{b}}=\frac{\left[r^{2}+(d r / d \theta)^{2}\right]^{3 / 2} \cos \beta_{\mathrm{c}}}{r^{2}+2(d r / d \theta)^{2}-r\left(d^{2} r / d \theta^{2}\right)} \omega_{\mathrm{c}} .
$$
$\kappa=-1$.

For scheme ' $\mathrm{U}$ ', $\kappa=1$ in Eq. (16); for scheme ' $\mathrm{V}$ ',

As mentioned, the gear billet should rotate for an additional cycle when $\mathbf{v}_{\mathrm{z}}^{*}$ moves a screw lead along the axle of the gear billet. Therefore,

$$
\int_{0}^{t} r \Delta \omega_{\mathrm{c}} d t=\int_{0}^{t} \tan \beta_{\mathrm{c}} v_{\mathrm{z}}^{*} d t \text {. Thus, }
$$




$$
\Delta \omega_{\mathrm{c}}=\left(v_{\mathrm{z}}^{*} \tan \beta_{\mathrm{c}}\right) / r .
$$

Consequently, $\omega_{\mathrm{c}}^{*}$ can be deduced from Eqs. (2) and (17).

$$
\omega_{\mathrm{c}}^{*}=\omega_{\mathrm{c}} \pm\left(\left(v_{\mathrm{z}}-\kappa v_{\mathrm{dz}}\right) \tan \beta_{\mathrm{c}}\right) / r
$$

where the ' + ' is adopted as the helix direction of the hob, which is in accordance with that of the gear; otherwise, the '-' is adopted.

According to Eqs. (13), (16) and (18), a six-axis linkage model based on diagonal hobbing is built by use of a method of equal arc-length for the gear billet such that the velocity of the hob remains constant [12]. $\omega_{\mathrm{b}}, v_{\mathrm{d}}$ and $v_{\mathrm{z}}$ are three independent fundamental frequencies, and the other axes move with them in a strict transmission ratio. The linkage model is as follows.

$$
\left\{\begin{aligned}
v_{\mathrm{x}} & =\frac{r^{3}\left(d^{2} r / d \theta^{2}\right)+(d r / d \theta)^{4}}{\left[r^{2}+(d r / d \theta)^{2}\right]^{2} \cos \beta_{\mathrm{c}}} \xi \\
v_{\mathrm{y}} & =r \frac{d r}{d \theta} \frac{r^{2}+2(d r / d \theta)^{2}-r\left(d^{2} r / d \theta^{2}\right)}{\left[r^{2}+(d r / d \theta)^{2}\right]^{2} \cos \beta_{\mathrm{c}}} \xi \\
\omega_{\mathrm{c}}^{*} & =\frac{r^{2}+2(d r / d \theta)^{2}-r\left(d^{2} r / d \theta^{2}\right)}{\left[r^{2}+(d r / d \theta)^{2}\right]^{3 / 2} \cos \beta_{\mathrm{c}}} \xi \pm \\
& \pm \frac{\left(v_{\mathrm{z}}-\kappa v_{\mathrm{dz}}\right) \tan \beta_{\mathrm{c}}}{r}
\end{aligned}\right.
$$

where $\xi=K m_{\mathrm{n}} \omega_{\mathrm{b}} / 2+\kappa v_{\mathrm{d}} \cos \lambda_{\mathrm{b}}$.

\section{VERIFYING BY VIRTUAL HOBBING}

According to linkage model (Eq. (19)), there are two implementing methods corresponding to the schemes ' $U$ ' $(\kappa=1)$ and ' $V$ ' $(\kappa=-1)$. Both of the two types of gears ('L' or ' $R$ ') can be hobbed by use of the two implementing methods, thus the possible arrangements are as follows: UL, UR, VL, VR. We want to verify these four working conditions by virtual hobbing using MATLAB before their use in practical applications.

A $3^{\text {rd }}$ order elliptic helical gear is a kind of typical non-circular helical gear for which the polar radius $r$ of the pitch curve changes with differing polar angles $\theta$, and has the essential characteristics of any noncircular helical gear. Consequently, a $3^{\text {rd }}$ order elliptic helical gear is analyzed as an example in this article and the conclusions drawn can be expanded to other non-circular helical gears with free pitch curve. The equation of the pitch curve of a $3^{\text {rd }}$ order elliptic helical gears is shown in Eq. (20) [16]. Its key parameters are as follows: $A=140 \mathrm{~mm} ; e=0.1 ; m_{\mathrm{n}}=8 \mathrm{~mm} ; \beta_{\mathrm{c}}=10^{\circ} 34^{\prime}$; $Z=35 ; \mathrm{b}=50 \mathrm{~mm} ; K=1 ; \lambda_{\mathrm{b}}=3^{\circ} 19^{\prime}$.

$$
r=A\left(1-e^{2}\right) /(1-e \cos 3 \theta) .
$$

The motion of each axis is determined according to Eq. (19). Each working condition will take 15 seconds to hob one cycle along the pitch curve of the gear and 300 seconds for the whole process. The processing parameters are shown in Table 1. A tool rack is shown in Fig. 4e), which can keep in pure rolling along the pitch curve of the non-circular gears in linkage models and then the tooth profile of gears can be enveloped. The tool paths are shown in Figs. 4a to $d$, which show that a non-circular helical gear can be hobbed correctly based on a diagonal process under each working condition.

Table 1. Processing parameters of the four working conditions

\begin{tabular}{cccc}
\hline Working conditions & $\omega_{\mathrm{b}}[\mathrm{rad} / \mathrm{s}]$ & $v_{\mathrm{z}}[\mathrm{mm} / \mathrm{s}]$ & $\kappa v_{\mathrm{d}}[\mathrm{mm} / \mathrm{s}]$ \\
\hline UL & 14.661 & -0.230 & 5.000 \\
\hline UR & 14.661 & -0.047 & 5.000 \\
\hline VL & 14.661 & -0.104 & -5.000 \\
\hline VR & 14.661 & -0.287 & -5.000 \\
\hline
\end{tabular}

As shown in Fig. 2, according to pure rolling, the linear velocity of the pitch curve at point $P$ is constant when both $\omega_{\mathrm{b}}$ and $v_{\mathrm{d}}\left(v_{\mathrm{dx}}\right)$ are constant, which can still meet the requirement of equal arc-length for the gear billet. Therefore, the tool paths of all four working conditions shown in Fig. 4 are evenly distributed along their pitch curves, and the profile accuracy of each tooth is uniform under every working condition. $v_{z}$ is controlled by an independent fundamental frequency and makes a linkage with other axes, which is assigned according to Table 1 for every working condition. Thus, $\mathbf{v}_{\mathbf{z}}^{*}$ determined by Eq. (2) is always $-0.167 \mathrm{~mm}$ for every working condition. Therefore, the axial accuracy of all teeth is also uniform under every working condition.

In short, a non-circular helical gear whether ' $\mathrm{L}$ ' or ' $R$ ' can be hobbed by use of the scheme ' $U$ ' or ' $\mathrm{V}$ '. Moreover, their tool paths show that the tooth accuracies under the four working conditions are uniform.

\section{DYNAMICS ANALYSIS FOR THE FOUR WORKING CONDITIONS}

For the four working conditions, the characteristics of linear (or angular) velocities (or accelerations) of each axis are analyzed respectively to compare their 

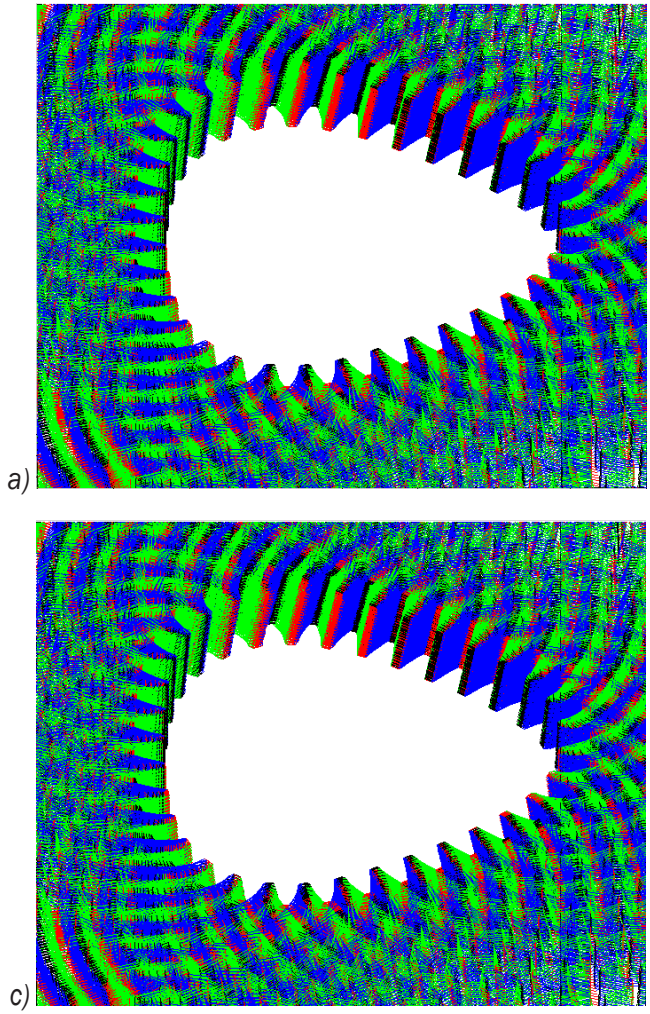
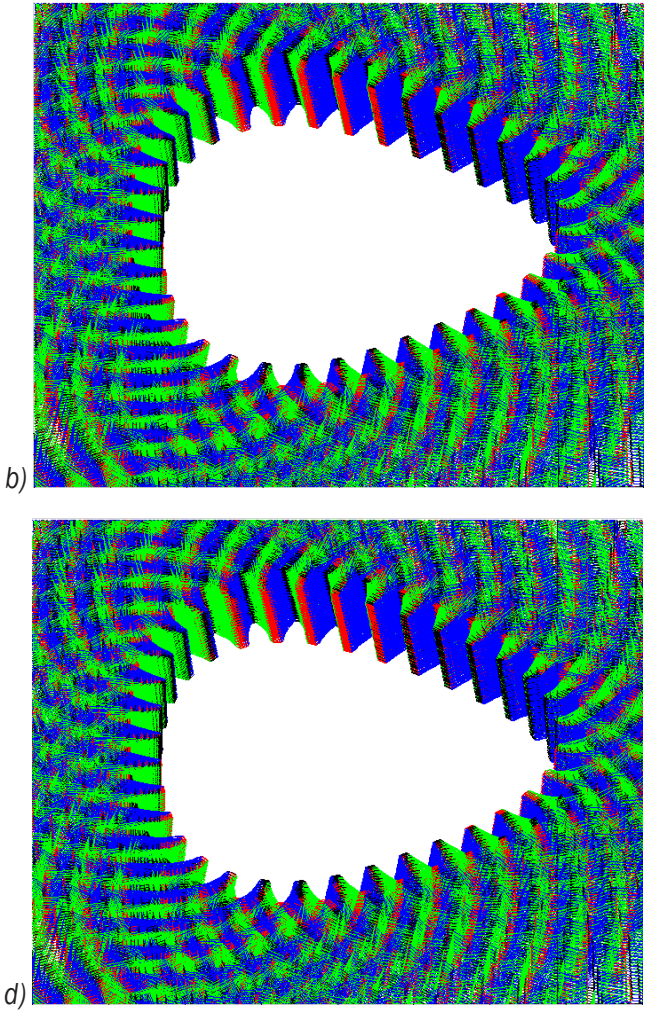

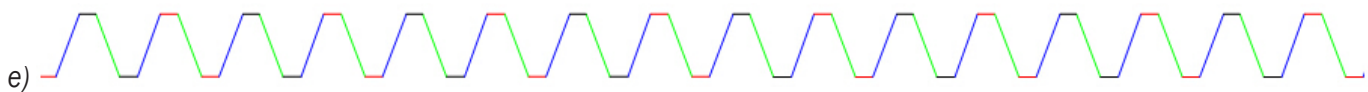

Fig. 4. Virtual hobbing non-circular helical gears based on a diagonal process; a) working condition 'UL', b) working condition 'UR', c) working condition 'VL', d) working condition 'VR', e) tool rack

dynamic performances. We work with the $3^{\text {rd }}$ order elliptic helical gear mentioned above by taking the values in Table 1 for $\omega_{\mathrm{b}}, v_{\mathrm{z}}$ and $v_{\mathrm{d}}$.

\subsection{Performance Analysis for Linear (or Angular) Velocities}

As shown in Fig. 5, curves $\omega_{\mathrm{c}}^{*}, v_{\mathrm{x}}$ and $v_{\mathrm{y}}$ under the four working conditions are drawn respectively using MATLAB as the polar angle of the pitch curve changes from 0 to $2 \pi$. As for $\omega_{c}^{*}$, shown in Fig. $5 a$, the largest difference between the working condition ' $U L$ ' and that of 'UR' is only about $0.3 \%$, while that between working condition 'VL' and 'VR' is about $0.4 \%$. An implication can be drawn that tendency to variation of curves $\omega_{c}^{*}$ in 'UL' and 'UR' are approximate, the same as in 'VL' and 'VR'. However, the range of $\omega_{c}^{*}$ in scheme ' $U$ ' ('UL' and 'UR') is significantly larger than that in scheme 'V" ('VL' and 'VR'). The former is about 1.2 times as much as the latter. As shown in Fig. 5b, it was found that curve $v_{x}$ in 'UL' accords well with that in 'UR', and curve $v_{\mathrm{x}}$ in 'VL' tallies totally with that in 'VR'. As shown in Fig.
$5 \mathrm{c}$, curve $v_{\mathrm{y}}$ in 'UL' accords similarly well with that in 'UR', and curve $v_{\mathrm{y}}$ in 'VL' tallies totally with that in 'VR'. This is because the helix direction of a gear has nothing to do with its pitch curve, and thus the different rotating direction of the teeth has no effect on $v_{\mathrm{x}}$ or $v_{\mathrm{y}}$. As for $v_{\mathrm{x}}$, the largest difference between scheme ' $U$ ' and scheme ' $V$ ' in Fig. $5 b$ is approximately $16.0 \%$; as for $v_{\mathrm{y}}$, the largest difference between scheme ' $U$ ' and scheme ' $V$ ' in Fig. $5 c$ is about $17.0 \%$. It is thus clear that different scheme ('U' or ' $V$ ') have different effects on $v_{\mathrm{x}}$, as well as $v_{\mathrm{y}}$.

\subsection{Performance Analysis for Linear (or Angular) Accelerations}

From Eqs. (9) and (16),

$$
\int_{0}^{\theta} \sqrt{r^{2}+(d r / d \theta)^{2}} d \theta=\frac{K m_{\mathrm{n}} \omega_{\mathrm{b}}+2 \kappa \nu_{\mathrm{d}} \cos \lambda_{\mathrm{b}}}{2 \cos \beta_{\mathrm{c}}} t .
$$

Horizontal axis $\theta$ in Fig. 5 can be transformed into corresponding hobbing time $t$ according to Eq. (21). Thus, all of curves $v(\omega)-\theta$ in Fig. 5 

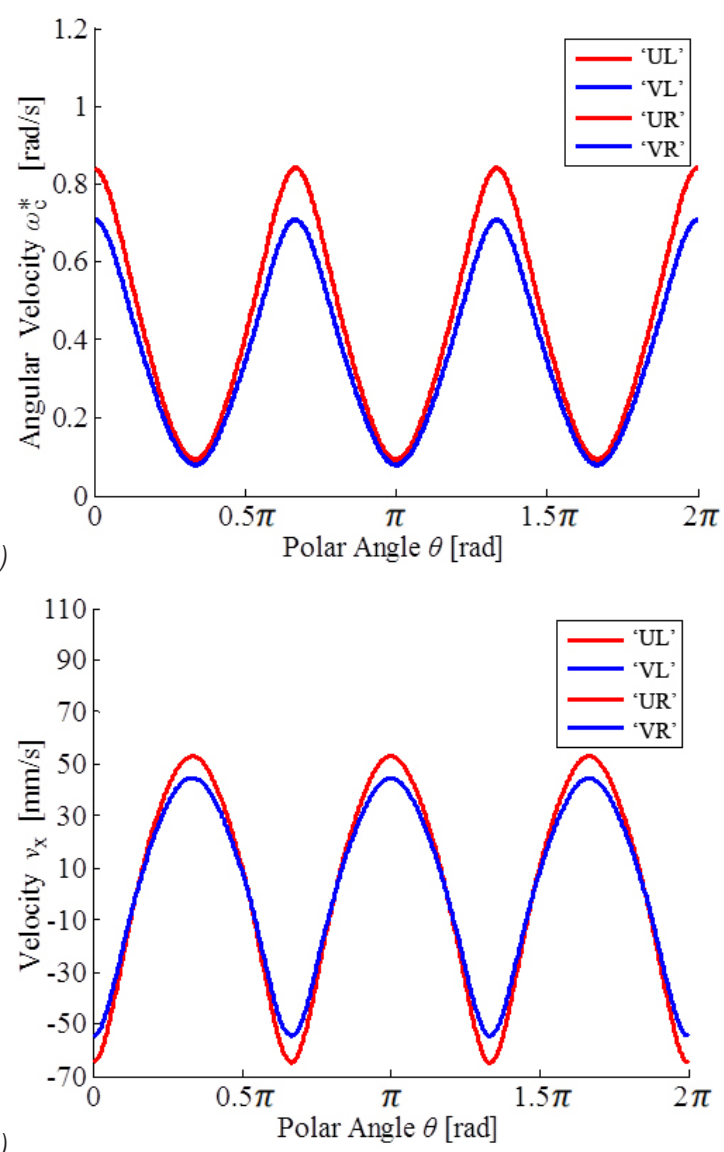

b)

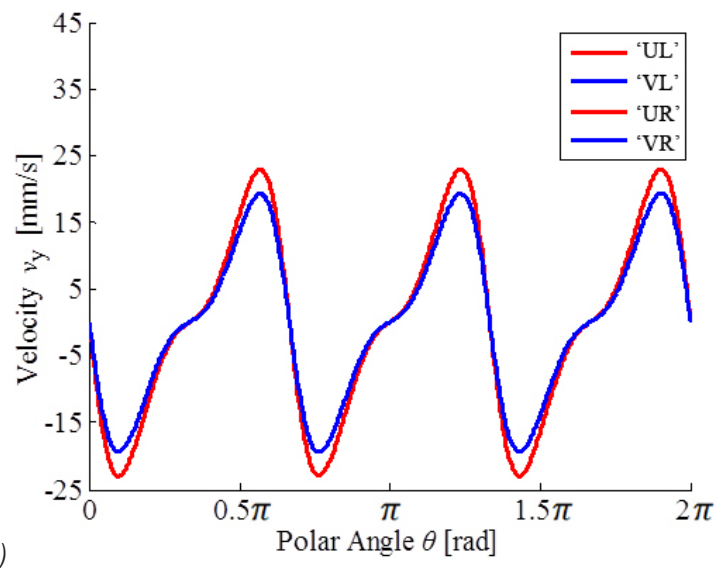

Fig. 5. Curves of $v(\omega)-\theta$; a) curve of $\omega_{\mathrm{c}}^{*}-\theta$, b) curve of $\left.v_{\mathrm{x}}-\theta, c\right)$ curve of $v_{\mathrm{y}}-\theta$

can be converted into curves $v(\omega)-t$. The curves characterized by some discrete points are fitted into some $n$-order polynomials by means of a function $p=\operatorname{polyfit}(t, v(\omega), n)$ in MATLAB [17]. The polynomials thus derived are differentiated by use of $p p=\operatorname{polyder}(p)$, of which the differential values $a(\alpha)$ at sequence time $t$ can be calculated using a function
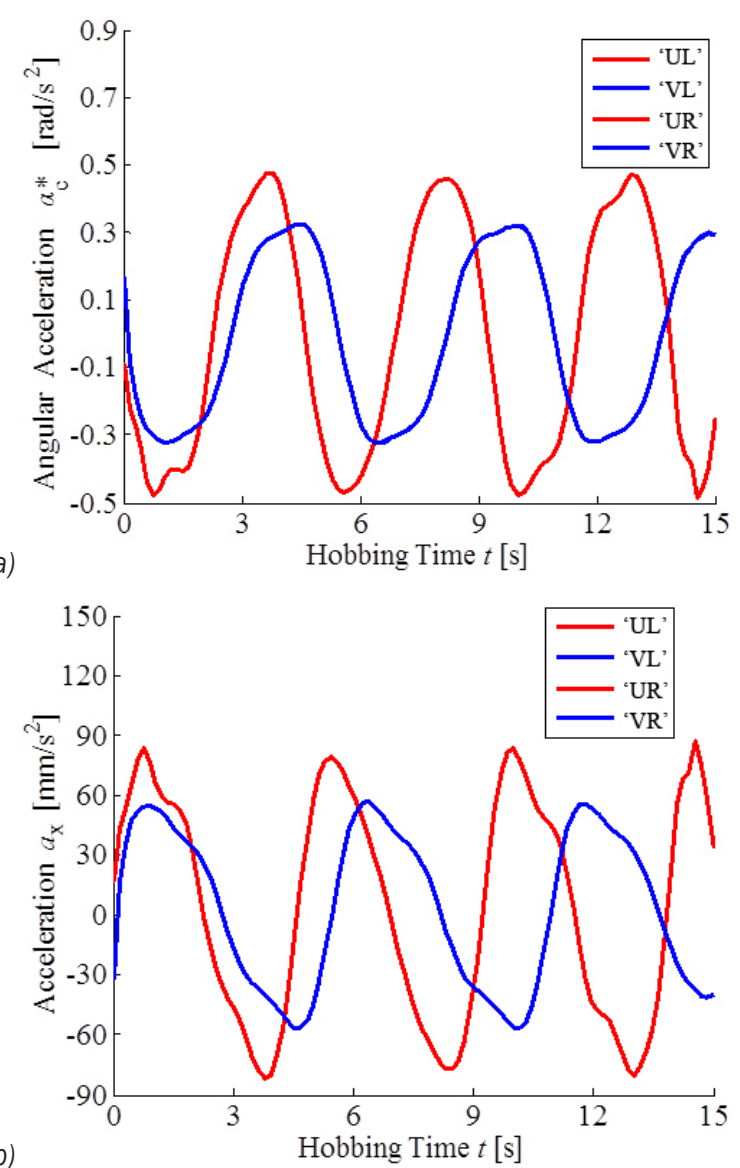

b)

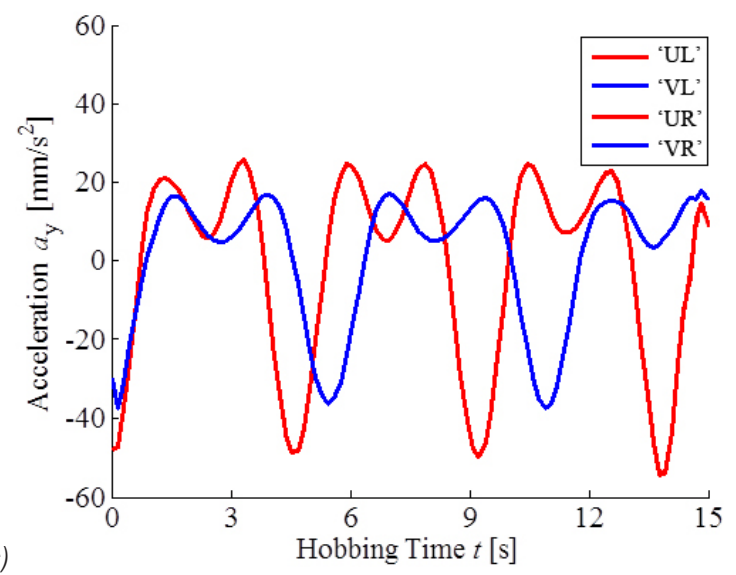

Fig. 6. Curve of $a(\alpha)-t$; a) curve of $\alpha_{\mathrm{c}}^{*}-t$, b) curve of $\left.a_{\mathrm{x}}-t, c\right)$ curve of $a_{\mathrm{y}}-t$

$a(\alpha)=\operatorname{polyval}(p p, t)$. Curves $a(\alpha)-t$ are derived and shown in Fig. 6.

As for $\alpha_{c}^{*}$ shown in Fig. 6a, the largest difference between the working condition 'UL' and that of 'UR' is less than $0.1 \%$. Similarly, curve $\alpha_{\mathrm{c}}^{*}$ in working condition ' $\mathrm{VL}$ ' is almost the same as that in working 
condition 'VR'. Nevertheless, the range of $\alpha_{\mathrm{c}}^{*}$ in scheme "U" ("UL" and "UR") is about 1.4 times as much as that in scheme ' $\mathrm{V}$ ' ('VL' and 'VR'). As shown in Fig. 6b, curve $a_{\mathrm{x}}$ in 'UL' accords well with that in 'UR', and curve $a_{\mathrm{x}}$ in 'VL' tallies totally with that in 'VR'. As shown in Fig. 6c, similarly, curve $a_{\mathrm{y}}$ in 'UL' accords well with that in 'UR', and curve $a_{\mathrm{y}}$ in 'VL' tallies totally with that in 'VR'. As shown in Fig. $6 \mathrm{~b}$, however, the value of $a_{\mathrm{x}}$ in scheme ' $\mathrm{U}$ ' is about 1.36 times as much as that in scheme ' $\mathrm{V}$ '. As shown in Fig. 6c, the value of $a_{\mathrm{y}}$ in scheme ' $\mathrm{U}$ ' is about 1.38 times as much as that in scheme ' $\mathrm{V}$ '.

In brief, as for $\omega_{\mathrm{c}}^{*}, v_{\mathrm{x}}, v_{\mathrm{y}}$ and $\alpha_{\mathrm{c}}^{*}, a_{\mathrm{x}}, a_{\mathrm{y}}$ in scheme ' $\mathrm{V}$ ', their variation ranges are relatively narrow, which is in favor of speed control for high speed hobbing and can thus ensure that the system has a better dynamic quality. The speed value of every axle in scheme ' $U$ ' is no more than $120 \%$ of the corresponding one in scheme ' $\mathrm{V}$ '. The acceleration value of every axle in scheme ' $U$ ' is no more than $140 \%$ of the corresponding one in scheme ' $V$ '. Since it may not result in a drop in control performance, scheme ' $U$ ' can also be adopted for medium-low speed. As for high speed, however, scheme ' $U$ ' is not suitable because excessive hobbing speeds or accelerations will reduce the control accuracy and dynamic quality of system. Moreover, a conclusion can be drawn that the speeds and accelerations of every axle in scheme ' $U$ ' or scheme ' $V$ ' will have no effect on the different rotating direction of the teeth.

\section{IMPLEMENTATION STRATEGIES FOR LINKAGE MODELS}

Being subject to the influences of cutter material, main shaft bearing, machine stiffness and so on, a gear hobbing machine should give priority to scheme ' $\mathrm{V}$ ' ('VL' or 'VR'), although all four working conditions mentioned can be adopted when hobbing speed is not high. The length of a hob axis should not be too long given the stiffness of the process system, which means that the length of many hob axes cannot meet the hobbing demand of gears with too long pitch curves or too wide teeth. That is because hobs move along only one direction in their axes under the four working conditions.

For higher speeds, a method called repeating axial shift can be applied to solve the above problem. Only scheme ' $\mathrm{V}$ ' is used in this method. The hob cuts along (or perpendicular to) its shaft at the beginning. As the meshing point $\mathrm{P}$ moves to the end of the hob axis, the hob will cut off along (or perpendicular to) its shaft and go back to the beginning with no cutting stroke and then cut in again. Thus, the meshing point P goes back to the beginning of hob axis, and so forth. In this method, a long idle travel time is indispensable. Moreover, because of the secondary feed, there are lots of connective cutting marks on the tooth flanks.

As for medium-low speed, a method called reciprocating axial shift can be applied to solve the above problem. Scheme ' $V$ ' is adopted firstly. When the meshing point $\mathrm{P}$ moves to the end of the hob axis, scheme ' $U$ ' is subsequently applied, in which point $\mathrm{P}$ moves in reverse from the end to the beginning. When point $\mathrm{P}$ reaches the beginning, scheme ' $\mathrm{V}$ ' is adopted again, and so forth. Because this gets rid of the deficiencies of repeating axial shift, this method should be given priority in applications.

\section{ANALYSIS FOR HOBBING EXPERIMENTS}

According to the linkage model in Eq. (19), a manufacturing module (including repeating axial shift and reciprocating axial shift) for non-circular helical gears has been developed based on a hobbing platform using ARM \& DSP \& FPGA [18], which has been used in a gear hobbing machine (STAR-2014 G). The $3^{\text {rd }}$ order elliptic helical gear mentioned using the method of reciprocating axial shift ('VL' \& 'UL') and the processing parameters shown in Table 1 is shown in Fig. 7. Four standard hobs [19] connected in series are installed on the hob axis, the parameters of which are as follows: $m_{\mathrm{n}}=8 \mathrm{~mm}, L_{\mathrm{b}}=132 \mathrm{~mm}, Z_{\mathrm{b}}=10$. This shows that non-circular helical gears can be hobbed correctly.

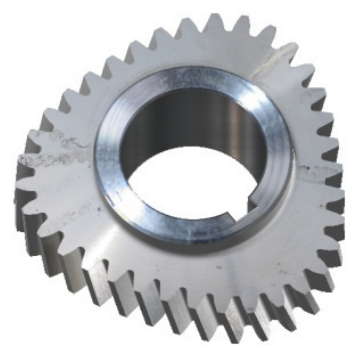

Fig. 7. $3^{\text {rd }}$ order elliptic helical gear, hobbed

To compare and analyze the properties of diagonal hobbing for non-circular helical gears, we conducted another experiment based on the method of non-diagonal hobbing at the same time. The nondiagonal hobbing experiment can be transformed from the diagonal one with the same efficiency by setting $v_{\mathrm{d}}=0$ and $v_{\mathrm{z}}=-0.167 \mathrm{~mm} / \mathrm{s}$. 


\subsection{Hob Life}

In the two experiments, the material used for the gear billets is 45 carbon steel and that of the hobs highspeed steel coated TiN. The wear standard of a hob is a permissible value $V B_{\text {per }}$ of flank wear at a normal wear stage [20]. The prescribed limits of $V B_{\text {per }}$ is $0.2 \mathrm{~mm} .3^{\text {rd }}$ order elliptic helical gears are hobbed using diagonal hobbing and non-diagonal hobbing separately in the range of wear standard. The measured values of wear width $V B$ on the flanks of the hobs are shown in Fig. 8 in the two experiments. On the one hand, the wear mass loss on the flank of hob reach $V B_{\text {per }}$ after hobbing 12 gears in non-diagonal hobbing. Therefore, $L_{\mathrm{m}}$ is $21358 \mathrm{~mm}$ according to Eq. (22) [20]. On the other hand, $L_{\mathrm{m}}$ is $311466 \mathrm{~mm}$ in diagonal hobbing up to the $V B_{\text {per }}$ after hobbing 175 gears.

$$
l_{\mathrm{m}}=\frac{Z b n}{\cos \left(\beta_{\mathrm{c}}\right)} .
$$

It was found that wear parts are mostly focused on the $8^{\text {th }}$ to the $21^{\text {st }}$ cutter teeth in non-diagonal hobbing. Moreover, wear appears particularly severe around the $16^{\text {th }}$ one. However, the $1^{\text {st }}$ to the 7 th cutter teeth and the $22^{\text {nd }}$ to the $35^{\text {th }}$ ones do not participate in hobbing and their wear is nearly zero. On the other hand, there is certain wear from the $2^{\text {nd }}$ cutter tooth to the $34^{\text {th }}$ one in diagonal hobbing. Particularly, the wear width $V B$ of the $6^{\text {th }}$ to the $31^{\text {st }}$ cutter teeth generally remains at around $0.193 \mathrm{~mm}$. A formula for hob life $T$ is shown in Eq. (23) [20], from which we can see that the hob life in diagonal hobbing is about 14.58 times longer than that in non-diagonal hobbing. In view of this, there is actually only one standard hob involved in cutting for non-diagonal hobbing and the other three hobs can be used latter, the actual ratio is about 3.68.

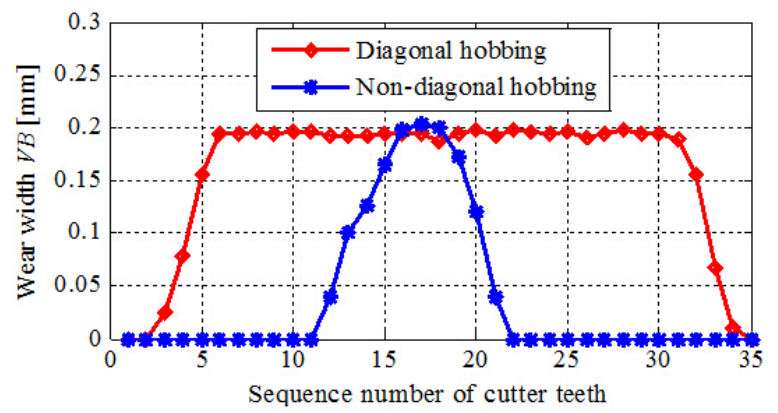

Fig. 8. Wear width of flank surface for two kinds of hobbing

$$
T=\frac{V B_{\mathrm{per}}}{v_{\mathrm{h}}} \cdot \frac{l_{\mathrm{m}}}{V B} .
$$

Obviously, the meshing point $\mathrm{P}$ (see Fig. 2) moves at a constant velocity along the pitch line of the hob in diagonal hobbing, in which every cutter tooth participates in hobbing equally and then stress or heat is uniformly distributed. Thus, hob life can be improved significantly.

\subsection{Accuracy of Teeth Profile}

As shown in Fig. 9, a pitch curve is drawn on the theoretical model of a gear in cross-section, which is then offset proportionally by a distance of $3 \mathrm{~mm}$ and $6 \mathrm{~mm}$ separately inwardly and outwardly [21]. Consequently, curves such as a, b, c, d, and e are formed. There are two intersections between each curve with both sides of each tooth, as shown in Fig. 9. Therefore, there are 350 intersections in all. The corresponding curves a, b, c, d, and e are curved slightly on the cross-section of the $3^{\text {rd }}$ order elliptic helical gear hobbed using a miniature milling cutter on an NC milling machine. The absolute coordinates of the intersections mentioned above on the $\mathrm{x}$-axis and $y$-axis can be measured by a coordinate measuring machine separately.

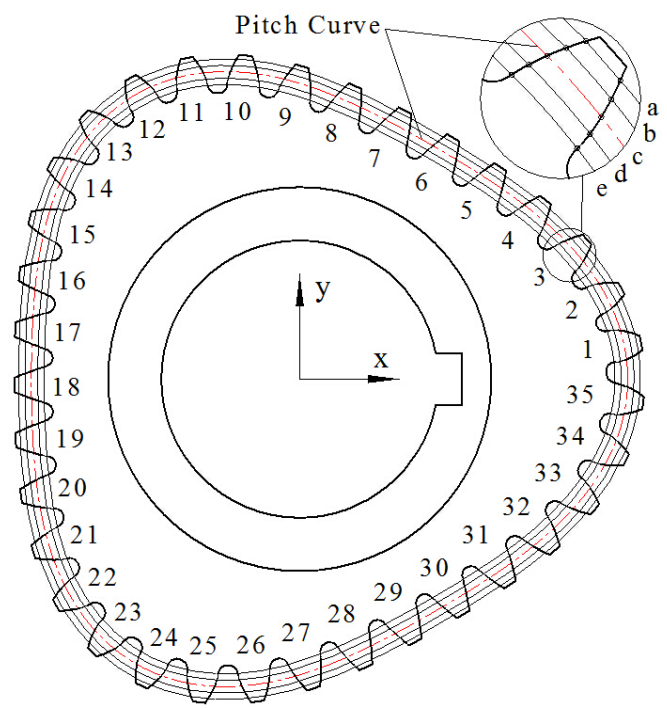

Fig. 9. Detecting point of teeth profile in cross-section

Order $\left\{\delta_{\mathrm{x}}\right\}$ is a set of errors between the measured values and the theoretical ones on the $\mathrm{x}$-axis, and $\left\{\delta_{\mathrm{y}}\right\}$ is that for the y-axis. Frequency distribution of $\left\{\delta_{\mathrm{x}}\right\}$ and that of $\left\{\delta_{\mathrm{y}}\right\}$ are shown in Tables 2 and 3 separately. As shown in Fig. 10, an error-distribution image of $\left\{\delta_{\mathrm{x}}\right\}$ and $\left\{\delta_{\mathrm{y}}\right\}$ is developed with the median of intervals as a horizontal axis and frequency as a vertical one. From Fig. 10, it can be found that both $\left\{\delta_{\mathrm{x}}\right\}$ and $\left\{\delta_{\mathrm{y}}\right\}$ are basically at a normal distribution 
[22], the errors of more than $99.43 \%$ points measured are in the interval of $[-0.100,0.100]$, which implies that the actual teeth profiles are consistent with the theoretical ones and have a high precision. Moreover, the errors of measured values in 1 st $12^{\text {th }}, 13^{\text {th }}, 3^{\text {th }}$, $24^{\text {th }}$, and $35^{\text {th }}$ tooth are concentrated in the interval $[-0.140,-0.060)$ or $(0.060,0.140]$ in Tables 2 and 3 . This indicates that the measured values on the teeth have a large error for the part of the pitch curve with a small curvature radius. That is to say, the larger the curvature radius of the part of pitch curve, the higher the precision of tooth accuracy.

Table 2. Frequency distribution of $\left\{\delta_{\mathrm{x}}\right\}$

\begin{tabular}{cccc}
\hline No. & Interval $[\mathrm{mm}]$ & Median $[\mathrm{mm}]$ & Freq. \\
\hline 1 & {$[-0.140,-0.100)$} & -0.120 & 1 \\
\hline 2 & {$[-0.100,-0.060)$} & -0.080 & 19 \\
\hline 3 & {$[-0.060,-0.020)$} & -0.040 & 85 \\
\hline 4 & $(-0.020,0.020)$ & 0 & 141 \\
\hline 5 & $(0.020,0.060]$ & 0.040 & 84 \\
\hline 6 & $(0.060,0.100]$ & 0.080 & 18 \\
\hline 7 & $(0.100,0.140]$ & 0.120 & 2 \\
\hline
\end{tabular}

Table 3. Frequency distribution of $\left\{\delta_{\mathrm{y}}\right\}$

\begin{tabular}{cccc}
\hline No. & Interval $[\mathrm{mm}]$ & Median $[\mathrm{mm}]$ & Freq. \\
\hline 1 & {$[-0.140,-0.100)$} & -0.120 & 1 \\
\hline 2 & {$[-0.100,-0.060)$} & -0.080 & 17 \\
\hline 3 & {$[-0.060,-0.020)$} & -0.040 & 83 \\
\hline 4 & $(-0.020,0.020)$ & 0 & 149 \\
\hline 5 & $(0.020,0.060]$ & 0.040 & 81 \\
\hline 6 & $(0.060,0.100]$ & 0.080 & 19 \\
\hline 7 & $(0.100,0.140]$ & 0.120 & 0 \\
\hline
\end{tabular}

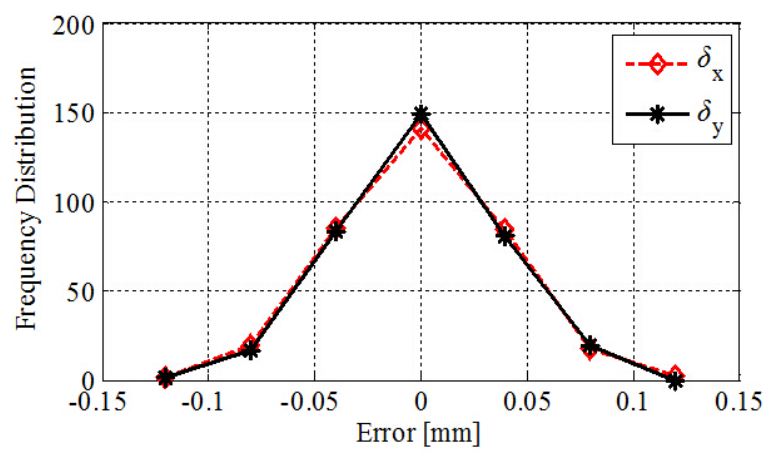

Fig. 10. Error-distribution of $\left\{\delta_{\mathrm{x}}\right\} \&\left\{\delta_{\mathrm{y}}\right\}$

\subsection{Microtopography of Tooth Flank}

As shown in Fig. 11, the 1 st tooth flanks of the $3^{\text {rd }}$ order elliptic helical gears obtained by the two hobbing methods are imaged respectively using a Scanning
Electron Microscope (SEM, $5.0 \mathrm{kV} 8.0 \mathrm{~mm} \times 8.00 \mathrm{k}$ ). The tooth flank shown in Fig. 11a is cut using nondiagonal hobbing, in which the cutting marks are approximately parallel with the gear axis. When two gears with the same surface features mesh together, their cutting marks occlude mutually and usually make the gear train vibrate, which not only reduces the stability of the gear driving system, but also increase the system noise [23]. In some cases, some troubles such as gear vibration and ultimately result in failures can be caused [24]. The tooth flank shown in Fig. $11 \mathrm{~b}$ is cut by the diagonal hobbing, in which the cutting marks are not parallel with the gear axis, and are mainly distributed as some S-shaped curves. Because of having different cutting-mark direction, pair of gears engage stably and do not occlude.
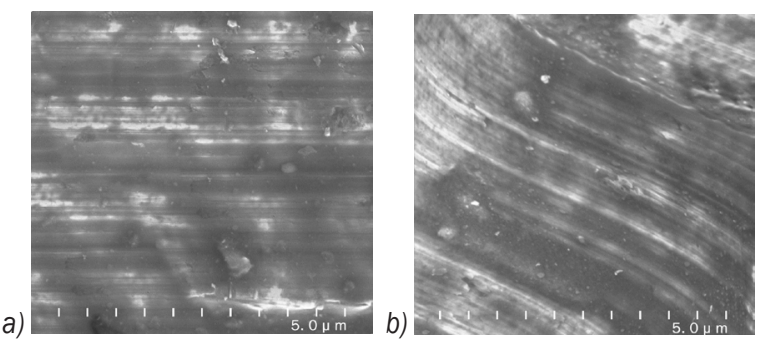

Fig. 11. SEM image of tooth flanks; a) non-diagonal hobbing, b) diagonal hobbing

\section{CONCLUSIONS}

Hobbing is a highly effective machining process. The traditional non-circular hobbing process keeps the hobs fixed in their axial positions, which means that the load and wear on the cutter tooth of the hob are extremely uneven. The hob life depends on the cutter tooth that has the largest amount of wear and thus hob life is extremely low.

1) The strategy of diagonal hobbing offers a possible solution, which can completely solve the issues mentioned. Moreover, four kinds of probable working conditions and linkage models have been provided, which have been verified by virtual hobbing. Their tool paths show that the tooth accuracies under the four working conditions are uniform.

2) Some conclusions drawn from the dynamics analysis: As for high-speed hobbing, scheme ' $\mathrm{V}$ ' should be given priority in applications because it has better dynamic qualities of velocity and acceleration versus scheme ' $U$ '. As for mediumlow speed hobbing, both scheme ' $U$ ' and ' $V$ ' can be used, although scheme ' $\mathrm{V}$ ' is better. The 
speed and acceleration for every axle in scheme ' $U$ ' or scheme ' $V$ ' has no effect on the different rotating direction of the teeth. As a result, two implementation strategies including repeating axial shift and reciprocating axial shift have been offered. The latter has been used in this article because it leaves no connective cutting marks on the tooth flanks and has no idle travel of the hob compared to the former.

3) These hobbing experiments demonstrate that the linkage model in Eq. (19) and its implementation strategies are both accurate and feasible. Moreover, diagonal hobbing is superior to nondiagonal hobbing in that the hob life of the former is 3.68 times longer that of the latter and the micro-topography on the teeth surface of the former can be more stable for transmission.

\section{NOMENCLATURE}

\begin{tabular}{ll}
$a$ & acceleration [mm $\left.\times \mathrm{s}^{-2}\right]$ \\
$A$ & semi-major axis [mm] \\
$b$ & tooth width [mm] \\
$e$ & eccentricity \\
$K$ & lobe of hob \\
$l$ & translational distance of tooling-rack \\
& midline [mm] \\
$l_{\mathrm{m}}$ & length of hobbing route [mm] \\
$L$ & length [mm] \\
$m$ & module [mm] \\
$n$ & number of gears \\
$r$ & polar radius [mm] \\
$S$ & turned arc-length of pitch curve of gear \\
\multicolumn{3}{c}{ billet [mm] } \\
$S(\mathrm{o}-\mathrm{xyz})$ & $\quad$ machine coordinate system \\
$S_{\mathrm{b}}\left(\mathrm{o}_{\mathrm{b}}-\mathrm{x}_{\mathrm{b}} \mathrm{y}_{\mathrm{b}} \mathrm{z}_{\mathrm{b}}\right) \quad$ cutting tool coordinate system \\
$S_{\mathrm{c}}\left(\mathrm{o}_{\mathrm{c}}-\mathrm{x}_{\mathrm{c}} \mathrm{y}_{\mathrm{c}} \mathrm{z}_{\mathrm{c}}\right) \quad$ workpiece coordinate system \\
$T$ & hob life [s] \\
$v$ & velocity [mm $\times \mathrm{s}^{-1}$ ] \\
$V B$ & value of flank wear [mm] \\
$V B_{\mathrm{per}}$ & permissible value of flank wear [mm] \\
$Z$ & number of teeth
\end{tabular}

Greek symbols

$\begin{array}{ll}\alpha & \text { angular acceleration }\left[\mathrm{rad} \times \mathrm{S}^{-2}\right] \\ \beta & \text { helical angle }[\mathrm{rad}] \\ \varphi & \text { rotating angle }[\mathrm{rad}] \\ \kappa & \text { symbol coefficient } \\ \lambda & \begin{array}{l}\text { lead angle }[\mathrm{rad}] \\ \text { angle between polar radius }\end{array} \\ \mu & \begin{array}{l}\text { of pitch curve }[\mathrm{rad}] \\ \text { polar angle }[\mathrm{rad}]\end{array} \\ \theta & \text { angular velocity }\left[\mathrm{rad} \times \mathrm{s}^{-1}\right]\end{array}$

$\Delta \omega \quad$ extra angular velocity $\left[\operatorname{rad} \times \mathrm{S}^{-1}\right]$

Subscripts

b hob

c gear billet

d hob axis

h pitch circle of hob

max maximum

n normal parameter

$\mathrm{t}$ transverse parameter

$\mathrm{x} \quad \mathrm{x}$-direction

y y-direction

$\mathrm{z} \quad \mathrm{z}$-direction

Superscripts

n normal component

* resultant parameter

\section{ACKNOWLEDGMENTS}

This work was financially supported by the Natural Science Foundation of Anhui Province of China (Grant No. 1408085ME94) and the Natural Science Research Project of Higher Education of Anhui Province of China [Grant No. KJ2013A039].

\section{REFERENCES}

[1] Jia, J.M., Gao, B. (2012). A novel non-circular planetary differential for off-road vehicles. China Mechanical Engineering, vol. 23, no. 3, p. 346-348, D0l:10.3969/j. issn.1004-132X.2012.03.021. (in Chinese)

[2] Qian, M., Yu, G., Jiang, C., Zhao, Y. (2014). Work principle and parameter optimization of rice-seedling transplanter with non-circular gears. Transactions of the Chinese Society for Agricultural Machinery, vol. 45, no. 6, p. 64-69, D0l:10.6041/j. issn.1000-1298.2014.06.011. (in Chinese)

[3] Lin, C., Hou, Y., Gong, H., Zeng, Q., Nie, L. (2011). Flow characteristics of high-order ellipse bevel gear pump. Journal of Drainage and Irrigation Machinery Engineering, vol. 29, no.5, p.379-385, D0l:10.3969/j.issn.1674-8530.2011.05.003. (in Chinese)

[4] Chen, J.N., Zhao, H.C., Wang, Y., Xu, G.H., Zhou, M. (2013). Kinematic modeling and characteristic analysis of eccentric conjugate non-circular gear \& crank-rocker \& gears train weft insertion mechanism. Journal of Donghua University (English Edition), vol. 30, no. 1, p. 15-20.

[5] Litvin, F.L., Gonzalez-Perez, I., Fuentes, A., Hayasaka, K. (2008). Design and investigation of gear drives with noncircular gears applied for speed variation and generation of functions. Computer Methods in Applied Mechanics and Engineering, vol. 197, no. 45-48, p. 3783-3802, DOI:10.1016/J.cma.2008.03.001.

[6] Mundo, D., Gatti, G., Dooner, D.B. (2009). Optimized five-bar linkages with non-circular gears for exact path generation. 
Mechanism and Machine Theory, vol. 44, no. 4, p. 751-760, DOI:10.1016/j.mechmachtheory.2008.04.011.

[7] Li, J.G., Wu, X.T., Mao, S.M. (2007). Numerical computing method of noncircular gear tooth profiles generated by shaper cutters. The International Journal of Advanced Manufacturing Technology, vol. 33, no. 11-12, p. 1098-1105, D0l:10.1007/ s00170-006-0560-0.

[8] Liu, Y.Y. (2014). Research on Gear Shaping Strategy for Internal Helical Non-Circular Gears and Performance Analyses for Linkage Models. Journal of Mechanical Science and Technology, vol. 28, no. 7, p. 2749-2757, Dol:10.1007/ s12206-014-0514-7.

[9] Liu, Y.Y. (2015). Study of Optimal Strategy and Linkage Model for External Non-Circular Helical Gears Shaping. Proceedings of IMechE Part C: Journal of Mechanical Engineering Science, vol. 229, no. 3, p. 493-504, D0l:10.1177/0954406214536700.

[10] Tan, W.M., Hu, C.B., Xian, W.J., Ou, Y. (2001). Concise mathematical model for hobbing non-circular gear and its graphic simulation. Chinese Journal of Mechanical Engineering, vol. 37, no. 05, p. 26-29, D0l:10.3901/ JME.2001.05.026. (in Chinese)

[11] Tian, F.Y., Hu, C.B., Jiang, Y.C. (2011). The simplest mathematical model and simultaneous-control structure for hobbing helical non-circular gear. Applied Mechanics and Materials, vol. 42, p. 284-288, D0l:10.4028/www.scientific. net/AMM.42.284.

[12] Liu, Y.Y., Han, J., Xia, L., Tian, X.Q. (2012). Hobbing strategy and performance analyses of linkage models for non-circular helical gears based on four-axis linkage. Strojniški vestnik - Journal of Mechanical Engineering, vol. 58, no. 12, p. 701708, D0I:10.5545/sv-jme.2012.524.

[13] Liu, Y.Y., Han, J., Xia, L., Zhang, G.Z. (2013). Research on Hobbing Process Strategy for Non-Circular Helical Gears and Performance Analyses for the Functional Models. Transactions of the Chinese Society for Agricultural Machinery, vol. 44, no. 5, p. 281-287, DOl:10.6041/j.issn.1000-1298.2013.05.049. (in Chinese)
[14] Gupta, K., Jain, N.K. (2014). Analysis and optimization of micro-geometry of miniature spur gears manufactured by wire electric discharge machining. Precision Engineering, vol. 38, no. 4, p. 728-737, DOl:10.1016/j.precisioneng.2014.03.009.

[15] Radi, H.A., Rasmussen, J.0. (2013). Principles of Physics. Springer, Berlin Heidelberg, New Delhi, Dol:10.1007/978-3642-23026-4.

[16] Litvin, F.L., Fuentes, A. (2004). Gear Geometry and Applied Theory. Second ed. Cambridge University Press, New York, DOl:10.1017/СВ09780511547126.

[17] Vosoughifar, H.R., Dolatshah, A., Shokouhi, S.K.S., Nezhad, S.R.H. (2013). Evaluation of fluid flow over stepped spillways using the finite volume method as a novel approach. Strojniški vestnik - Journal of Mechanical Engineering, vol. 59, no. 5, p. 301-310, D0l:10.5545/sv-jme.2012.669.

[18] Santos, M.J.S.F., Santos, J.B.D. (2011). FPGA-based control system of an ultrasonic phased array. Strojniški vestnik Journal of Mechanical Engineering, vol. 57, no. 2, p. 135-141, DOl:10.5545/sv-jme.2010.178.

[19] GB/T 28252-2012 (2012). Hobs for Pre-Grinding Gear. China National Standardization Management Committee, Beijing. (in Chinese)

[20] Editorial board for gearing book. (2004). Gearing book. Volume two. China Machine Press, Beijing.

[21] Elise, M. (2014). Autodesk Autocad 2014 Fundamentals. Createspace, New York.

[22] GB/T 4889-2008 (2008). Statistical interpretation of data - Techniques of estimation and tests relating to means and variances of normal distribution. China National Standardization Management Committee. Beijing. (in Chinese)

[23] Ognjanović, M., Kostić, S.Ć. (2012). Gear unit housing effect on the noise generation caused by gear teeth impacts. Strojniški vestnik - Journal of Mechanical Engineering, vol. 58, no. 5, p. 327-337, D0l:10.5545/sv-jme.2010.232.

[24] Ognjanović, M.B., Ristić, M., Vasin, S. (2013). BWE traction units failures caused by structural elasticity and gear resonances. Technical Gazette - Tehnički vjesnik, vol. 20, no. 4, p. 599-604. 